\title{
Dietary restrictions in healing among speakers of lquito, an endangered language of the Peruvian Amazon
}

Kevin A Jernigan

\begin{abstract}
Background: Ethnobotanical research was carried out with speakers of lquito, a critically endangered Amazonian language of the Zaparoan family. The study focused on the concept of "dieting" (siyan++ni in lquito), a practice involving prohibitions considered necessary to the healing process. These restrictions include: 1) foods and activities that can exacerbate illness, 2) environmental influences that conflict with some methods of healing (e.g. steam baths or enemas) and 3) foods and activities forbidden by the spirits of certain powerful medicinal plants. The study tested the following hypotheses: $\mathrm{H} 1$ - Each restriction will correlate with specific elements in illness explanatory models and $\mathrm{H} 2$ - Illnesses whose explanatory models have personalistic elements will show a greater number and variety of restrictions than those based on naturalistic reasoning.

Methods: The work was carried out in 2009 and 2010 in the Alto Nanay region of Peru. In structured interviews, informants gave explanatory models for illness categories, including etiologies, pathophysiologies, treatments and dietary restrictions necessary for 49 illnesses. Seventeen botanical vouchers for species said to have powerful spirits that require diets were also collected.

Results: All restrictions found correspond to some aspect of illness explanatory models. Thirty-five percent match up with specific illness etiologies, 53\% correspond to particular pathophysiologies, 18\% correspond with overall seriousness of the illness and $18 \%$ are only found with particular forms of treatment. Diets based on personalistic reasoning have a significantly higher average number of restrictions than those based on naturalistic reasoning.

Conclusions: Dieting plays a central role in healing among lquito speakers. Specific prohibitions can be explained in terms of specific aspects of illness etiologies, pathophysiologies and treatments. Although the Amazonian literature contains few studies focusing on dietary proscriptions over a wide range of illnesses, some specific restrictions reported here do correspond with trends seen in other Amazonian societies, particularly those related to sympathetic reasoning and for magical and spiritual uses of plants.
\end{abstract}

Keywords: Iquito, Ethnomedicine, Dietary Taboos, Peru, Endangered Languages

\section{Background}

\section{Dietary Proscriptions in Healing}

Dietary restrictions accompanying the healing process have been reported from geographically widespread locations, including Africa [1,2], Europe [3], North America [1], Southeast Asia [4,5], and South America [6-8]. The connection between diet and medicine forms an important part of the classical and modern humoral

Correspondence: awatidiam@yahoo.com

Department of Ethnobotany, University of Alaska, Fairbanks, Kuskokwim Campus, 201 Akiak Dr., Bethel, AK, USA traditions of India, China, ancient Greece and medieval Europe [9-12]. Some authors [13,14] have also pointed out the importance of dietary context for understanding the physiological effects of medicinal plants from a biomedical perspective. A number of recent review articles [15-17] have also treated dietary taboos in a broader social context.

In the Amazonian case, the ethnomedical literature [18-23] has tended to discuss dietary restrictions in the context of spiritual traditions related to ayahuasca and other psychoactive plants, as well as their role in learning 
how to heal in that tradition $[19,21]$. However, the healing systems of many Amazonian societies [24-27] rely on cures of both a physical and spiritual nature. Attitudes toward medicinal plants also reflect this duality. On one hand, plants are thought to have physical effects on the body. On the other, they are believed to possess spirits that can actively participate in the healing process. Physical cures are often common knowledge that any adult possesses, while spiritual cures tend to be the province of specialists. Lenaerts argues, based on his work with the Ashéninka and other Amazonian societies [25,28], that these two forms of healing are not simply parallel systems coexisting in the same place. Rather, the spiritual level is the one of real power and efficacy, while the physical is merely useful for relieving symptoms. Other authors $[8,29,30]$ have made similar observations in other Amazonian societies.

This paper presents the results of research on the relationship between illness explanatory models (EMs) [31] and corresponding restrictions on diet and activities for speakers of Iquito, a critically endangered [32] language of the Peruvian Amazon. The explanatory model is a framework for describing a cognitive model of how illness works in terms of five components: 1) etiology, 2) onset of symptoms, 3) pathophysiology, 4) prognosis and 5) treatment [31]. This framework allows for a detailed examination of the rationales for dietary restrictions within the logic of a given ethnomedical system. The first hypothesis of this research is: H1 - Each restriction will correlate in a systematic way with one or more elements of the illness explanatory models. In other words, one might find that fish with sharp teeth are never eaten for illnesses involving internal bleeding, or that patients given enemas must always avoid rain and cold.

The Iquito are no exception to the general Amazonian trend of plurality of medical reasoning, making reference to spiritual, emotional, humoral and contaminationrelated illness etiologies, among others. However, some of these etiologies appear to have been adopted fairly recently. Study participants said that their ancestors attributed spiritual causes to any illness that did not have an obvious physical cause. Taking that claim as a cue, and following the observation of various authors $[25,28-30]$ in favor of the primacy of spiritual over naturalistic healing modalities in other Amazonian societies, the second research hypothesis is: H2 - Illnesses whose explanatory models have personalistic elements will show a greater number and variety of restrictions than those based on naturalistic reasoning. For example, one would expect to find greater restrictions when a plant spirit or witchcraft is believed to be involved, than for cures based on humoral reasoning.

\section{History of the lquito Language}

Iquito is a language of the Zaparoan family, spoken by roughly twenty people, living in two villages in the Alto Nanay region of the north-eastern Amazon (Figure 1). According to early Spanish colonial reports, the language once extended over the area between the Tigre, Mazán and Amazonas rivers. The Iquito moved away from the major rivers from the $17^{\text {th }}$ to the $19^{\text {th }}$ centuries to avoid mission settlements and slave raids. By the early $20^{\text {th }}$ century, they started to form larger settlements downriver, including the village of San Antonio, on the Pintoyacu river, where this study took place [33,34].

Although mestizo (mixed native and European) settlers arrived with the rubber boom in the 1920s [34], the Iquito were essentially monolingual through the $1930 \mathrm{~s}$. With the death of the Iquito curaca (traditional leader) in 1944, the patrones (rubber bosses) consolidated their power, controlling the native population with a system of debt peonage. The newcomers brought a very negative attitude toward the Iquito language and discouraged its use, sometimes with violent means. By the end of the 1950s, most adults were already bilingual in Spanish and many children did not learn Iquito at all [33].

The 1950s and 60s saw another influx of mestizo settlers. Mixed marriages were common, and children in those families mostly did not learn Iquito. At the same time, new epidemics of flu, malaria and other infectious diseases killed many older monolingual speakers. By the 1990s, Spanish had largely replaced Iquito in everyday interactions.

Currently, none of the 20 or so speakers remaining is less than 50 years old. Negative feeling towards the language still exists, although it has diminished. In the last decade, linguists have been working on an IquitoSpanish dictionary [35] and on bilingual educational materials. The research described in this paper is part of a larger project representing the first study of Iquito ethnobotany and will hopefully contribute in some modest way to recent efforts [33,35-37] to document the language.

\section{Methods}

The study took place from 2009 to 2010, principally in the village of San Antonio Pintoyacu, in the Alto Nanay region of Loreto, Peru. Authorization for conducting research was obtained from the Peruvian Ministry of Agriculture (no. 324-2009-INENA-DGFFS-DGEFFS). Upon arriving in San Antonio, a meeting took place to discuss the study goals and the research plan, and to give community members a chance to ask questions and voice any concerns they might have. All participants gave verbal prior informed consent (PIC), and the research followed ethical guidelines adopted by the American Anthropological Association [38]. 


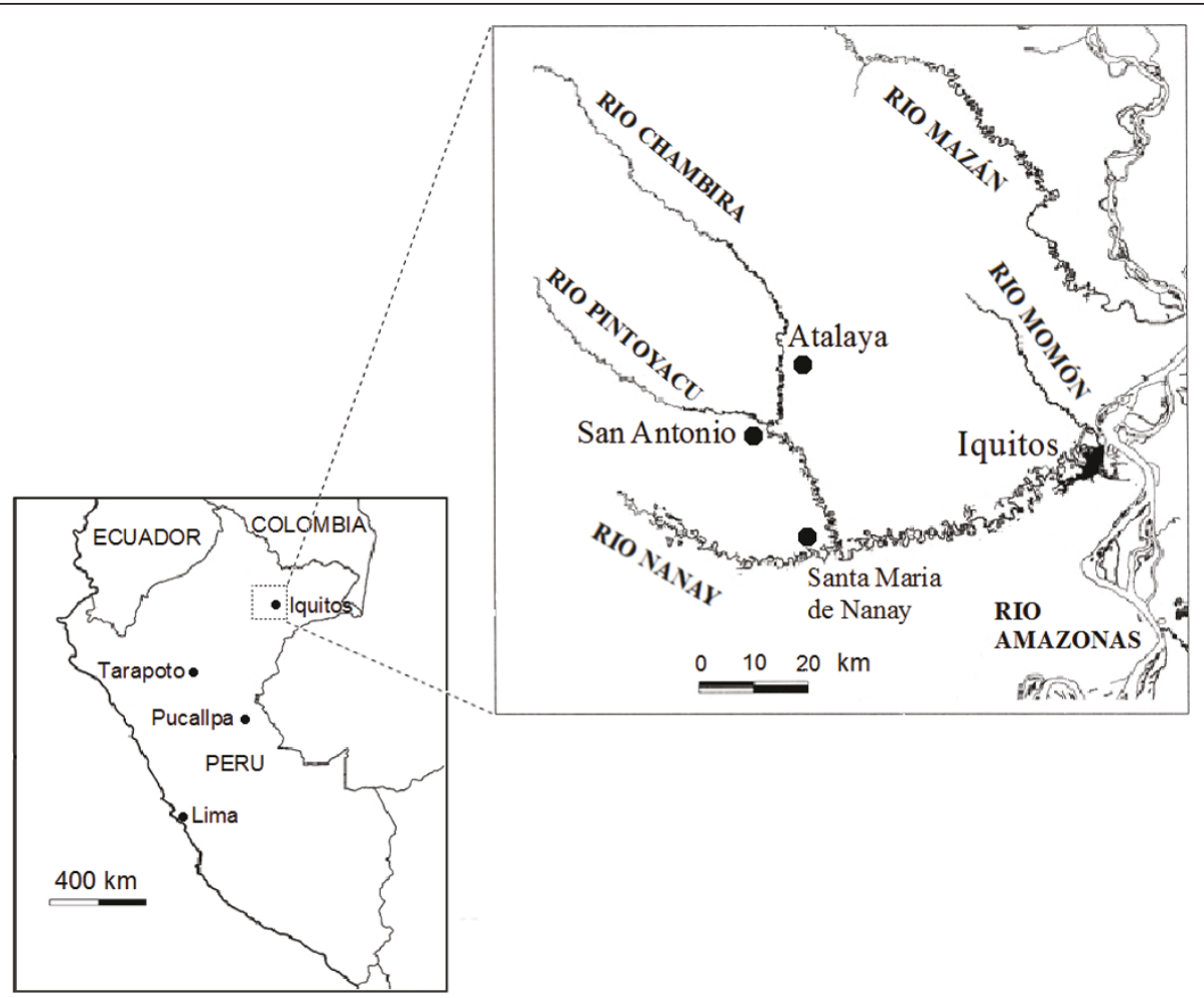

Figure 1 Map of the study area.

Of approximately twenty remaining Iquito speakers, six were recruited in San Antonio to participate in the study. Four of those provided the bulk of the data described in this article, while two others helped to further clarify and expand upon the data. Two non-speakers provided additional assistance with collection of botanical voucher specimens in the community of Atalaya (Figure 2), on the Chambira river. Five participants are bilingual in Spanish, while one is the last semi-monolingual speaker of Iquito. Although a larger sample would be ideal in a study of this kind, the very small number of fluent speakers who are also experts in medicinal plants greatly limited the participant pool. Some speakers did not value ethnobotanical knowledge due to years of repression of their indigenous identity [34]. Interviews were carried out primarily in Spanish, although much Iquito vocabulary relevant to illnesses and medicinal plants was collected as well. Note that Iquito plant and illness names provided in the text are shown in bold and italics, while Spanish names are given in italics. The Iquito character "+" represents a close central unrounded vowel.

In structured interviews, participants named 49 illness categories. Explanatory models were collected for each category, including etiologies, pathophysiologies and treatments. Informants described the types of dietary restrictions required for each treatment, including the foods and activities avoided and the length of time.
They also explained the reason for the diet, whether due to a plant spirit, the method of ingestion, or to avoid making the illness worse.

Seventeen voucher specimens were collected for plant species requiring special diets. These correspond to 14 botanical families. All vouchers were deposited in the herbarium of the Universidad Nacional de la Amazonía UNAP, in Iquitos, Peru.

\section{Results and Discussion}

\section{An Overview of Illness Categories and Explanatory Models}

Table 1 shows the 49 illness categories informants mentioned in the interviews. They cover a range of internal and external complaints as well as some magical conditions. A few local illness terms and culture-bound syndromes require explanation. Aquíraja (choque de aire in Spanish) involves diarrhea and vomiting and is thought to come from being struck by a strong wind carrying bad spirits or harmful environmental influences. Corazonada is a dangerously strong heartbeat that comes from arguing with one's spouse. Empacho is a digestive illness said to be caused by bad diet, involving intestinal swelling, headache, vomiting and diarrhea. Isíicu (sarna in Spanish) refers to a variety of skin infections. Informants recognized several types, including ácusana ('red') isíicu, characterized by red, itchy spots, musutina ('white') 


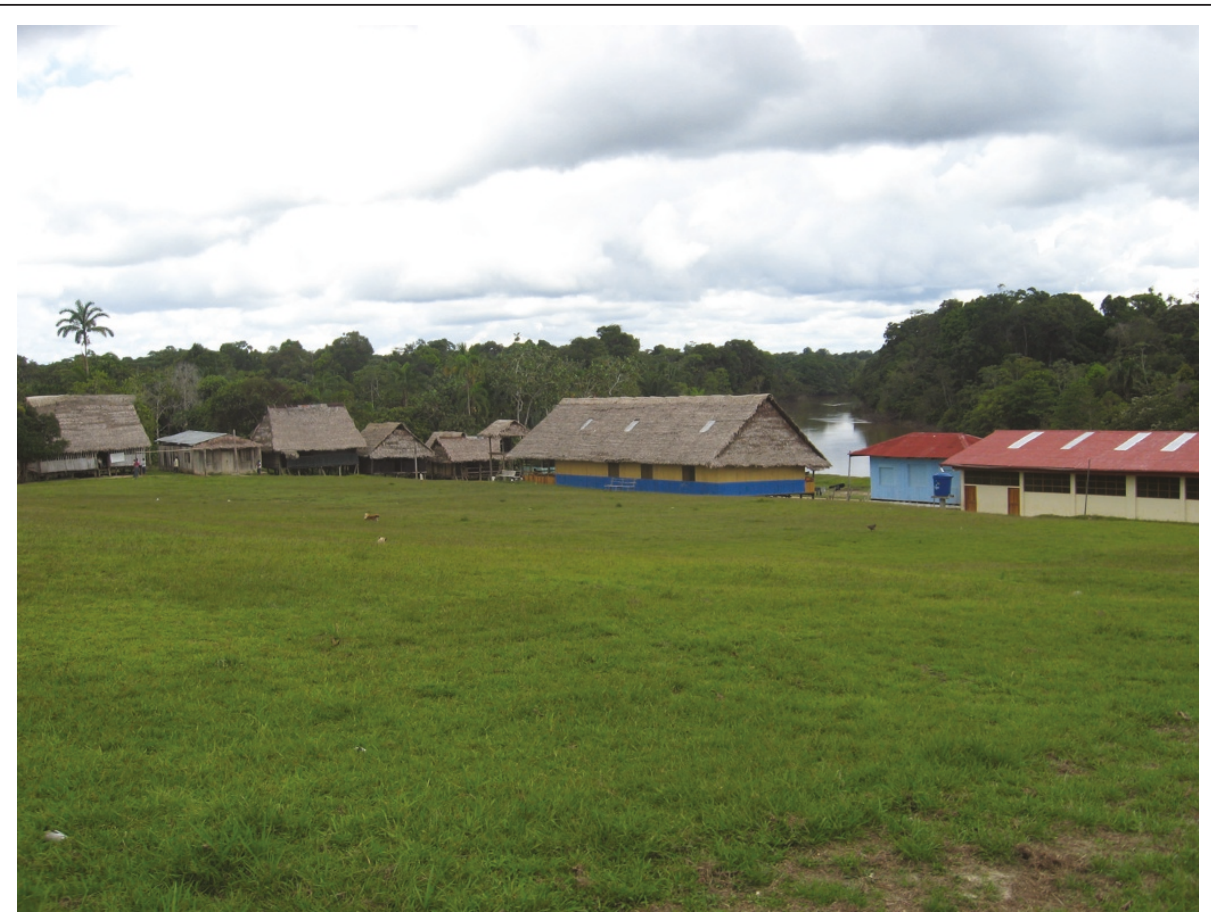

Figure 2 The community of Atalaya, Alto Nanay region, Loreto, Peru.

Table 1 Illnesses and Corresponding Diets

\begin{tabular}{|c|c|c|}
\hline ILLNESS & EXPLANATORY MODEL & DIET \\
\hline \multicolumn{3}{|l|}{ DIGESTIVE ILLNESSES } \\
\hline aquíraja (see text) & bad air, spirits & wind \\
\hline colic & temperature & spicy, cold \\
\hline constipation & bad food (too dry, certain fruits) & none \\
\hline diarrhea (simple) & temperature, dirty water, bad food & spicy, cold, heat, soup \\
\hline dysentery & temperature, dirty water & spicy, pork, cold, heat, soup, oil \\
\hline empacho (see text) & bad food, temperature & pork, cold, soup \\
\hline parasites & bad food, walking barefoot & sweet \\
\hline stomach ache & temperature & spicy, cold \\
\hline \multicolumn{3}{|l|}{ BITES AND STINGS } \\
\hline bullet ant bite & poisoning, mechanical & spicy \\
\hline scorpion sting & poisoning, mechanical & spicy, toothed animals, sex, cold, heat \\
\hline snake bite & poisoning, mechanical & $\begin{array}{l}\text { spicy, sour, pork, toothed fish and animals, sex, cold, } \\
\text { heat }\end{array}$ \\
\hline stingray sting & poisoning, mechanical & sex, cold \\
\hline \multicolumn{3}{|l|}{ EXTERNAL PROBLEMS } \\
\hline acariasis & parasites, bad hygiene & bad blood \\
\hline burns & physical & spicy, sex, heat \\
\hline isíicu (see text) & bad blood, sympathetic magic, bad hygiene & bad blood \\
\hline leishmaniasis & microbios (see text), spirits & $\begin{array}{l}\text { spicy, pork, toothed fish and animals, bad blood, sex, } \\
\text { cold, heat }\end{array}$ \\
\hline mouth sores & bad blood, sympathetic magic & none \\
\hline $\begin{array}{l}\text { múcuaay+ itúuja (see } \\
\text { text) }\end{array}$ & rainbow, sun, fog, bad air & spicy, heat \\
\hline pus-filled boils & bad blood, physical & spicy, bad blood, cold \\
\hline
\end{tabular}


Table 1 Illnesses and Corresponding Diets (Continued)

\begin{tabular}{|c|c|c|}
\hline wounds & mechanical & spicy, cold, heat \\
\hline \multicolumn{3}{|l|}{ FEVER RELATED } \\
\hline bronchitis & bad air, temperature & spicy, pork, sex, cold \\
\hline cholera & bad air, spirits, bad water & sweet, spicy, pork, soup, sex, cold, heat \\
\hline fever & temperature & cold, heat \\
\hline flu & bad air, spirits & spicy, sex, cold, heat \\
\hline malaria & $\begin{array}{l}\text { bad water, bad food, bad blood, mosquitoes, sexually transmitted, } \\
\text { microbios (see text) }\end{array}$ & spicy, pork, sex, cold, heat \\
\hline measles & bad air, spirits & $\begin{array}{l}\text { spicy, sour, toothed fish and animals, soup, sex, cold, } \\
\text { heat, oil }\end{array}$ \\
\hline tabardillo (see text) & temperature & cold, heat \\
\hline whooping cough & bad air, spirits & $\begin{array}{l}\text { sweet, spicy, sour, pork, toothed fish and animals, soup, } \\
\text { sex, cold, heat }\end{array}$ \\
\hline \multicolumn{3}{|l|}{ OTHER ILLNESSES } \\
\hline anemia & bad blood, lack of blood, microbios (see text), bad hygiene & sweet \\
\hline corazonada (see text) & emotional & none \\
\hline ear infections & temperature & cold, wind \\
\hline eye problems & mechanical, temperature, bad air & spicy, heat, spider webs in the eyes \\
\hline dislocations & mechanical & spicy, exertion \\
\hline fractures & mechanical & spicy, exertion \\
\hline general weakness & lack of blood, malnutrition & none \\
\hline head ache & temperature, bad blood & none \\
\hline haemorrhages & temperature & $\begin{array}{l}\text { sweet, spicy, sour, toothed fish and animals, soup, sex, } \\
\text { heat, exertion }\end{array}$ \\
\hline hernia & physical & spicy, sex, cold, exertion \\
\hline insomnia (in children) & temperature, lack of blood & none \\
\hline kidney problems & temperature, bad water & spicy, pork, toothed fish and animals, alcohol \\
\hline liver problems & bad or strong food and drink, temperature & spicy, pork, toothed fish and animals alcohol \\
\hline love problems & emotional & none \\
\hline pulsario (see text) & emotional & spicy, sour, toothed fish and animals, sex \\
\hline rheumatism & temperature & spicy, sex, cold, heat \\
\hline saladera (see text) & personalistic & hunting animals in forest, being seen by people \\
\hline sobreparto (see text) & mechanical & cold \\
\hline $\begin{array}{l}\text { temper tantrum (in } \\
\text { children) }\end{array}$ & emotional & none \\
\hline uterine problems & temperature, mechanical, microbios (see text) & $\begin{array}{l}\text { spicy, sour, toothed fish and animals, soup, sex, cold, } \\
\text { heat, alcohol }\end{array}$ \\
\hline witchcraft & personalistic & $\begin{array}{l}\text { spicy, sour, pork, toothed fish and animals, bad blood, } \\
\text { sex, cold }\end{array}$ \\
\hline
\end{tabular}

isíicu, involving white spots that are not painful, and $s$ +ríca, which causes white, itchy patches [35]. Múcuaay + itúuja - literally "rainbow burn" is a rash caused by exposure to a rainbow, the sun or mist. Pulsario is a worm that lives in the lower abdomen and grows bigger with emotional stress. Saladera involves persistent bad luck, especially in hunting. Sobreparto is an illness women may suffer after giving birth that involves diarrhea, body pain and fever. Tabardillo is a high fever caused by bathing too quickly after working in the sun.
As already noted, informants said the old Iquito attributed spiritual causes to any illness without an obvious physical origin. Infectious diseases in particular, such as measles and whooping cough were said to have a spirit like a person (niatíja - literally "mother" in Iquito). When a wave of epidemics came with the first mestizo settlers of the 1920s, people said the spirits flew through the air like angels searching for people to infect. The Iquito were not unique in this regard, Chaumeil mentions a similar belief among the neighboring Yagua 
[29], as does Bellier [39] for the Maihuna. Another type of personalistic etiology involves witchcraft. Witches are said to attack by a variety of means, including causing an invisible phlegm-like substance to lodge in the victim's body, producing severe pain.

Currently, witchcraft is still taken seriously in San Antonio, but belief in illness spirits has fallen out of favor. Study participants were more inclined to invoke humoral explanations, including excessive temperature and aquíraja - "bad air or wind." These EMs are broadly similar to humoral theories of health found in many parts of Central and South America [11,13]. Scholars have debated whether these ideas originated independently in the New World [40,41], or were simply borrowed from the Spanish [11]. The illness category $\boldsymbol{s}+\boldsymbol{m}+\boldsymbol{s i n} \boldsymbol{i}$ - "rheumatism" is a good example of humoral reasoning. When a person is exposed to night air, rain, wind or frigid bath water, the cold can stay in the bones and joints, causing pain and discomfort. Heat from the sun or from cooked foods and beverages can cause ipanaca - 'fever,' and enter bodily organs, potentially causing them damage. Moving too rapidly from one temperature extreme to another can also be harmful. Some informants say kidney problems can arise from taking a cold bath too soon after working in the hot sun. The rapid change causes the blood to become viscous and not circulate properly, which also harms internal organs.

Study collaborators attributed some illnesses to bad water or food. Standing water is commonly associated with $\boldsymbol{t a n +}+\boldsymbol{c a}$ - "malaria." It is considered harmful because animals defecate in it, or because it contains "microbios." The later term is ambiguous, as it is used for small visible organisms such as insect larvae as well as for microbes in the biomedical sense. Simple diarrhea (without blood or mucous) is blamed on eating greasy foods on an empty stomach, while intestinal parasites are said to come from consuming sweet fruits like ripe plantains and caimito (Pouteria caimito). The old Iquito took purges such as ácuta (Banisteriopsis caapi) and curarina (Potalia amara) often to cleanse impurities from the body, but such treatments have fallen out of use in recent times.

Some illnesses result from contamination of the blood. Healthy blood is considered key to maintaining overall good health. Lenaerts [25] has noted similar beliefs among the Ashéninka. One of the most common illnesses attributed to bad blood is pisáqui - "pus-filled boils." Contamination can come from eating the meat of certain animals like tapirs, whose blood is dark and considered to be dangerously strong. Blood-related illnesses and skin problems in general are also said to come from eating fish with spotted patterns. This is an example of sympathetic reasoning, whereby foods are thought to transfer particular qualities to people who eat them. Similarly, babies are susceptible to $\boldsymbol{m + ' + r i a a c a ~ - ~}$ "mouth sores," when a breastfeeding mother consumes spotted fish. Some people said biting flies and mosquitoes can contaminate the blood because they also bite dogs or wild animals such as snakes and transfer that foreign blood a person's body.

A few illness etiologies do not fit easily into any of the above categories. Getting dirt in an eye from running into spider webs in the forest causes carijáquica - "eye pain." Intestinal parasites are thought to infect people who walk barefoot, through the soles of the feet. Many informants noted that doctors told them malaria comes from mosquito bites, although some were skeptical about that explanation. Some illnesses have emotional causes, including the culturally bound syndromes corazonada and pulsario mentioned above.

\section{The Role of Dieting in Healing}

Avoiding certain foods and activities is often a necessary part of the healing process for Iquito speakers of San Antonio. Informants used the Spanish term dietar or the Iquito siyan++ni - "to diet" to describe this process. All collaborators related examples of people who became more ill or died from failing to follow expected restrictions.

Three main reasons for restrictions were given: 1) some foods and activities can exacerbate an illness, 2) some methods of administration (i.e. steam baths or enemas) leave a patient susceptible to harm from hot or cold environmental influences, 3) some healing plants possess spirits that require the patient to avoid certain foods or activities. In the first category, the diet is explained in terms of the etiology and pathophysiology of the illness. In the second and third, the restrictions are required to avoid conflicting with the treatment itself.

The following section describes common classes of dietary restrictions mentioned for two or more illnesses. These are grouped into categories and presented in terms of illness explanatory models.

\section{Spicy Foods}

Avoidance of spicy foods, in particular, $\boldsymbol{n a p}+\boldsymbol{q u} \boldsymbol{i}$ - "hot pepper" (Capsicum frutescens), is the most common dietary proscription, mentioned for $63 \%$ of illnesses (Table 1). This restriction applies especially for bites, stings, infectious diseases and illnesses involving internal organs. Pepper forms an important part of the traditional Iquito diet in such dishes as jicuriáaca, a soup made with manioc beer and meat or fish. However, it is also considered to be potentially quite harmful for people in a weakened state due to illness. One informant noted that pepper warms the blood and can burn internal organs, including the stomach, liver and kidneys.

\section{Environmental Influences}

Restrictions on environmental influences are found for $61 \%$ of total illnesses, making this the second most 
common category. Rain, night air and cold foods are said to exacerbate illnesses involving fevers, gas, diarrhea and serious bites or sores. Hot influences, including strong sun, cooked foods and being too near a cooking fire interfere with recovering from fevers, burns and wounds. Wind is dangerous for patients suffering from the culture-bound syndrome aquiraja - "bad air," or from ear infections.

Sometimes temperature extremes must be avoided even when they were not the original cause of the illness. For example, cold can enter a sore while a person is bathing and make it worse. Some methods of curing also leave a person vulnerable to harm from excessive temperatures. Exposure to cold foods, beverages or environmental influences after taking an enema or steam bath can cause intestinal swelling or death. It is interesting that some very similar humoral reasoning can be found in other parts of the world. For example, among Malays, both hot and cold influences are dangerous for fevers while cold influences are bad for digestive illness [42].

\section{Meat and Fish}

Restrictions on meat and fish are also quite common, found for $45 \%$ of total illnesses. Pork is considered one of the most potentially harmful because of its high fat content and because pigs eat garbage. This restriction does not seem to correspond with any particular category of illness. However, it does correspond to total number of diet items for a given illness. In other words, the more restrictions a given illness has, the more likely pork will be one of them. The average number of restrictions when pork is included is 5.3. The average for illnesses not including pork as a restriction is 2.4. Results of a two-tailed Mann Whitney U test [43] give a $P$ value of $<0.001$, which is considered a highly statistically significant difference, by standard criteria.

Through sympathetic reasoning, the meat of fish and mammals with sharp teeth is said to be harmful for those recovering from problems with internal organs or serious bites or stings. Those foods are also forbidden to anyone suffering from witchcraft, since sharp teeth invoke the magical darts witches are thought to use to harm their victims. In his study of dietary restrictions in Búzios island, São Paolo State, Brazil, Begossi [44]has also noted that carnivorous fish are avoided by people recovering from illness.

As previously mentioned, the meat of tapirs, peccaries and fish with spots is associated with bad blood. Those foods are harmful to anyone suffering from a skin infection.

Sex

Sexual abstinence is considered important for recovering from $37 \%$ of total illnesses, particularly for bites, stings, and some illnesses involving fevers or problems with internal organs. One informant maintained that sex causes the blood to circulate excessively and to penetrate the intestines. He also noted that it is dangerous because the soul momentarily escapes from the body. Another noted that women and men have differing humors, and also likened the prohibition to similar ones pertaining to meat.

\section{Sour}

Sour foods, including some fruits and itíniija - "manioc beer" are forbidden while recuperating from $14 \%$ of total illnesses. This prohibition does not appear to correspond to any particular kind of illness, but instead correlates with the total number of dietary restrictions. Results of a two-tailed Mann Whitney U test show diets including sour foods have a significantly higher average number of restrictions than those that do not.

\section{Soup}

Meat and fish prepared in a soup must be avoided for a number of illnesses involving bodily secretions such as blood, diarrhea and phlegm (14\% of total illnesses). The logic behind this prohibition appears to be sympathetic.

\section{Sweet}

People with parasites or diarrhea (10\% of total illnesses) must not consume sweet foods, including many fruits and manioc beer that has not fully fermented. Such foods are said to feed parasites and cause them to increase in number.

\section{Alcohol}

Distilled spirits are incompatible with $8 \%$ of total illnesses, particularly those affecting internal organs, especially the kidney, liver and uterus. One informant said that alcohol can burn these organs.

Oil

Oily foods are contraindicated for $8 \%$ of illnesses. This prohibition does not correspond to any particular illness category, but instead appears to correlate with the total number of dietary restrictions. Results of a two-tailed Mann Whitney U test show diets including oily foods have a significantly higher average number of restrictions than those that do not.

\section{Exertion}

Physical activity interferes with recovery from a few illnesses ( $8 \%$ of the total) with obvious mechanical etiologies, such as hernia and fractures.

\section{Diets Required By Plant Spirits}

In traditional Iquito belief, all plants have spirits, but some particularly powerful medicinal species are said to be celoso - "jealous," because they require anyone who ingests them to follow rigorous diets. Seventeen vouchers were collected for species in this category (Table 2).

When plants with "jealous" spirits are given to treat illness, diets tend to be more extensive than what is required simply to avoid exacerbating illnesses. In fact, 
Table 2 Plants with spirits that require diets

\begin{tabular}{|c|c|c|c|c|}
\hline SPECIES & VCH. & $\begin{array}{l}\text { COMMON } \\
\text { NAME }\end{array}$ & USE & DIET \\
\hline \multicolumn{5}{|l|}{ ANACARDIACEAE } \\
\hline Spondias mombin L. & 416 & $\begin{array}{l}m+\text { tiija } \\
\text { nap+nija }\end{array}$ & uterine problems & $\begin{array}{l}\text { spicy, sour, pork, toothed fish and animals, bad blood, sex, cold, } \\
\text { heat }\end{array}$ \\
\hline \multicolumn{5}{|l|}{ APOCYNACEAE } \\
\hline $\begin{array}{l}\text { Tabernaemontana macrocalyx } \\
\text { Müll. Arg. }\end{array}$ & 403 & $\begin{array}{l}\text { uchu } \\
\text { sanango }\end{array}$ & $\begin{array}{l}\text { rheumatism, body pain, } \\
\text { chronic sores }\end{array}$ & $\begin{array}{l}\text { salt, sweet, sour, pork, toothed fish and animals, bad blood, soup, } \\
\text { sex, heat, wind, oil, alcohol, manioc, exertion }\end{array}$ \\
\hline \multicolumn{5}{|l|}{ ARACEAE } \\
\hline Dieffenbachia sp. & 402 & sapatíqui & $\begin{array}{l}\text { altars the effects of } \\
\text { ayahuasca }\end{array}$ & $\begin{array}{l}\text { salt, sweet, spicy, sour, pork, toothed fish and animals, bad blood, } \\
\text { soup, sex, heat, wind, alcohol, manioc, exertion }\end{array}$ \\
\hline Dieffenbachia smithii Croat & 401 & áqu+siiti & $\begin{array}{l}\text { altars the effects of } \\
\text { ayahuasca }\end{array}$ & $\begin{array}{l}\text { salt, sweet, spicy, sour, pork, toothed fish and animals, bad blood, } \\
\text { soup, sex, heat, wind, alcohol, manioc, exertion }\end{array}$ \\
\hline \multicolumn{5}{|l|}{ BIGNONIACEAE } \\
\hline Mansoa alliacea A.H. Gentry & 335 & $m++^{\prime}+s+y+$ & $\begin{array}{l}\text { fever, flu, saladera (see } \\
\text { text) }\end{array}$ & $\begin{array}{l}\text { spicy, sour, pork, toothed fish and animals, bad blood, sex, cold, } \\
\text { heat }\end{array}$ \\
\hline \multicolumn{5}{|l|}{ CELASTRACEAE } \\
\hline $\begin{array}{l}\text { Maytenus macrocarpa (Ruiz \& } \\
\text { Pav.) Briq. }\end{array}$ & 391 & chuchuhuasi & rheumatism & $\begin{array}{l}\text { salt, sweet, spicy, sour, pork, toothed fish and animals, bad blood, } \\
\text { soup, sex, cold, heat, wind, oil, alcohol, manioc, exertion }\end{array}$ \\
\hline \multicolumn{5}{|l|}{ CLUSIACEAE } \\
\hline Tovomita cephalostigma Vesque & 385 & suníina & learning medicine & $\begin{array}{l}\text { salt, sweet, spicy, sour, pork, toothed fish and animals, bad blood, } \\
\text { soup, sex, cold, heat, wind, oil, alcohol, manioc, exertion, isolation }\end{array}$ \\
\hline \multicolumn{5}{|l|}{ EUPHORBIACEAE } \\
\hline Hura crepitans L. & 415 & catahua & treating witchcraft & $\begin{array}{l}\text { salt, sweet, spicy, sour, pork, toothed fish and animals, bad blood, } \\
\text { soup, sex, cold, heat, wind, oil, alcohol, manioc, exertion }\end{array}$ \\
\hline \multicolumn{5}{|l|}{ MALPIGHIACEAE } \\
\hline $\begin{array}{l}\text { Banisteriopsis caapi (Spruce ex } \\
\text { Griseb.) C.V. Morton }\end{array}$ & 426 & ácuta & $\begin{array}{l}\text { cleans the stomach, } \\
\text { visionary, learning } \\
\text { medicine }\end{array}$ & $\begin{array}{l}\text { salt, sweet, spicy, sour, pork, toothed fish and animals, bad blood, } \\
\text { soup, sex, heat, wind, alcohol, manioc, exertion }\end{array}$ \\
\hline \multicolumn{5}{|l|}{ MENISPERMACEAE } \\
\hline Abuta grandifolia Aubl. & 382 & $\begin{array}{l}\text { motelo } \\
\text { sanango }\end{array}$ & rheumatism, chills & $\begin{array}{l}\text { salt, sweet, spicy, sour, pork, toothed fish and animals, bad blood, } \\
\text { soup, sex, cold, heat, wind, oil, alcohol, manioc, exertion }\end{array}$ \\
\hline \multicolumn{5}{|l|}{ MORACEAE } \\
\hline Ficus insipida Willd. & 328 & ojé & parasites & $\begin{array}{l}\text { salt, sweet, spicy, sour, pork, toothed fish and animals, bad blood, } \\
\text { sex, cold, heat, oil }\end{array}$ \\
\hline \multicolumn{5}{|l|}{ OLACACEAE } \\
\hline Minquartia sp. & 374 & huacapú & anemia & $\begin{array}{l}\text { salt, sweet, spicy, sour, pork, toothed fish and animals, bad blood, } \\
\text { soup, sex, cold, heat, wind, oil, alcohol, manioc, exertion }\end{array}$ \\
\hline \multicolumn{5}{|l|}{ POACEAE } \\
\hline Paspalum sp. & 363 & gramalote & ear ache & other natural or pharmaceutical remedies \\
\hline \multicolumn{5}{|l|}{ PHYTOLACCACEAE } \\
\hline Petiveria alliacea $\mathrm{L}$. & 393 & mucura & saladera & being seen by other people, hunting animals in forest \\
\hline \multicolumn{5}{|l|}{ SOLANACEAE } \\
\hline Brunfelsia grandiflora D. Don & 413 & sanango & $\begin{array}{l}\text { rheumatism, body pain, } \\
\text { saladera }\end{array}$ & $\begin{array}{l}\text { salt, sweet, spicy, sour, pork, toothed fish and animals, bad blood, } \\
\text { soup, sex, cold, heat, wind, oil, alcohol, manioc, exertion, isolation }\end{array}$ \\
\hline $\begin{array}{l}\text { Brugmansia flaveolens (Humb. \& } \\
\text { Bonpl. ex Willd.) Bercht. \& C. Presl }\end{array}$ & 358 & isúuna & learning medicine & $\begin{array}{l}\text { salt, sweet, spicy, sour, pork, toothed fish and animals, bad blood, } \\
\text { soup, sex, cold, heat, wind, oil, alcohol, manioc, exertion, isolation }\end{array}$ \\
\hline \multicolumn{5}{|l|}{ ZINGIBERACEAE } \\
\hline Renealmia alpinia (Rottb.) Maas & 428 & $\begin{array}{l}\text { naquijina } \\
\text { mirija }\end{array}$ & saladera & being seen by other people, hunting animals in the forest \\
\hline
\end{tabular}


two restrictions, manioc and salt, are only found for plants in this group. Oral ingestion generally carries the most restrictions, particularly when it is an infusion or decoction in water. When plants are prepared in alcohol, diets are often much looser, but potency is also weakened.

Other plants in this group were used to learn how to be a paanáana - a specialist in spiritual healing. This process required months of isolation, strict sexual abstinence and avoidance of any strong foods, so that the spirit of the plant would appear and teach the dieter how to heal. In the most extreme cases, dieters were said to eat only the leaves of asúraaja (Manihot esculenta) and ám++ca (Phytolacca rivinoides). Informants maintained that their ancestors learned medicine mainly from isúuna (Brugmansia suaveolens) and ácuta (Banisteriopsis caapi). Interestingly, the primary admixture plants for Banisteriopsis caapi in San Antonio are Dieffenbachia (called $\boldsymbol{m}+$ $+\boldsymbol{m}+\boldsymbol{+} \boldsymbol{t} \boldsymbol{i}$ in Iquito or 'chacruna' in Spanish). Only one other literature reference (López Vinatea 2000) could be found mentioning this genus as an ayahuasca admixture. Study participants said other magical plants were learned after contact with mestizos and the arrival of colonists from other places. One informant, for example, said she learned from Lamas Quechua settlers that quión (Hedychium sp.) is capable of showing a person in dreams what kind of healer he can become.

The results of breaking diets with "jealous" plants are often more serious than simply making the illness worse. They are said to punish or bewitch people who break the diet. Some consequences are relatively minor. For example, if a person consumes sugar too soon after taking sanango (Brunfelsia grandiflora), he will get white spots on the head. Similarly, one informant said the old Iquito did not used to diet properly when taking ácuta (Banisteriopsis caapi), and thus, often suffered skin rashes. Later, healers from outside taught people to avoid sex and eat only very bland foods for a period of time after taking ayahuasca. Other punishments are much more serious. Breaking a diet with ojé (Ficus insipida) will punish a diet breaker by making him go crazy as the tree's white resinous sap comes out of all bodily orifices.

\section{Other}

A few restrictions apply only to a single illness. A person with an eye infection must avoid running into spider webs in the forest. Dirt in webs is considered harmful to the eye and is regarded as a possible cause of infections. To cure the culture bound syndrome saladera, the victim must go far into the forest and bathe with a mixture of urine and strong smelling plants such

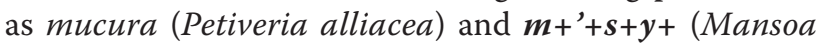
alliacea). He must avoid being seen by anyone else during this process and refrain from hunting any animal he encounters there.

\section{Addressing the Hypotheses}

The first hypothesis, that each restriction will correlate in a systematic way with one or more elements of the illness explanatory models, is supported by the data. Seventeen distinct dietary restrictions were mentioned two or more times in the interviews. All correlate to some aspect of the illness EMs. Six (35\%), (wind, heat, cold, bad blood, sweet foods and exertion) correspond to particular illness etiologies. Nine (53\%), (spicy foods, heat, cold, toothed animals and fish, sex, soup, sweet foods, alcohol and exertion) correspond to specific illness pathophysiologies. Two (12\%), (heat and cold), correspond to treatments administered as enemas or steam baths. Three prohibitions (18\%), (oily foods, sour foods and pork) correspond only to the overall seriousness of an illness. Three restrictions (18\%), (salt, manioc and isolation) are only found in cases of treatments involving powerful plant spirits.

The data also clearly support the second hypothesis that diets based on explanatory models with personalistic reasoning will show a differing number of and kinds of restrictions than those based on naturalistic reasoning. The former category includes all diets required by plant spirits and those for magical illnesses such as witchcraft and saladera. The average number of prohibitions for personalistic EMs is 9.4, while the average for naturalistic EMs is 3.1. Results of a two-tailed Mann Whitney U test show a highly statistically significant difference.

\section{Conclusions}

Restrictions of diet and activities play a central role in healing among Iquito speakers, and their ethnomedical system cannot be properly understood without taking them into account. Such prohibitions can be explained in terms of specific aspects of illnesses and their treatments. In general, restrictions will be more extensive for illnesses whose cause or treatment has a strong spiritual dimension.

Some prohibitions found among the Iquito correspond with trends seen in other Amazonian societies. Some authors have noted the importance of restrictions for magical and spiritual uses of plants, among mestizos $[19,23]$ and other indigenous societies [8]. Valadeau et al. [8] report that the Yanesha employ similar sympathetic reasoning, for example, in prohibiting meat from animals with sharp teeth to anyone suffering snake bite. The Ashéninka [25] share analogous ideas about contamination from eating certain species of animals.

Commonalities with other Amazonian societies raise the question of which ideas found in San Antonio have been borrowed. Some of the most salient medicinal plants participants mentioned, such as sanango (Brunfelsia grandiflora) and ojé (Ficus insipida) are only known by names of obvious Spanish or Quechua origin. Also, many important illness categories, including culture-bound syndromes 
such as saladera have no Iquito name. Future research could involve comparative studies in neighboring indigenous or mestizo communities to examine what aspects of Iquito diet beliefs appear to be unique to them and which appear to be pan-Amazonian.

\section{Acknowledgements}

This research was sponsored by a grant from the National Science Foundation (0754434). I would like to thank members of the communities San Antonio de Pintoyacu and Atalaya, especially Hermenegildo Díaz Cuyasa, Jaime Pacaya Inuma, Ema Llona Yareja and Ligia Inuma Inuma. The author would also like to thank two anonymous reviewers who provided helpful suggests for improving this article.

\section{Competing interests}

The author declares that they have no competing interests.

Received: 14 March 2011 Accepted: 11 July 2011

Published: 11 July 2011

\section{References}

1. Hughs CC: Ethnomedicine. In International Encyclopedia for the Social Sciences. Volume 5. Edited by: Sills, DL. New York: MacMillan; 1968.

2. Janzen J: The Quest for Therapy in Lower Zaire Berkeley: University of California Press; 1982.

3. Tagarelli G, Tagarelli A, Piro A: Folk medicine used to heal malaria in Calabria (southern Italy). Journal of Ethnobiology and Ethnomedicine 2010, 6:27 [http://www.ethnobiomed.com/content/6/1/27].

4. De Boer HJ, Lamxay V: Plants used during pregnancy, childbirth and postpartum healthcare in Lao PDR: A comparative study of the Brou, Saek and Kry ethnic groups. Journal of Ethnobiology and Ethnomedicine 2009, 5:25[http://www.ethnobiomed.com/content/5/1/25].

5. Virapongse A: Ethnomedicine and materia medica used by Kui traditional healers in northeast Thailand. Master's thesis Khon Kaen University, Pharmaceutical Botany and Pharmacognosy; 2006.

6. McCallum C: The body that knows: From Cashinahua epistemology to a medical anthropology of lowland South America. Medical Anthropology Quarterly 1996, 10:347-372.

7. Reeve ME: Concepts of illness and treatment practice in a Caboclo community of the Lower Amazon. Medical Anthropology Quarterly 2000, 14(1):96-108

8. Valadeau C, Alban Castillo J, Sauvain M, Lores AF, Bourdy G: The rainbow hurts my skin: medicinal concepts and plants uses among the Yanesha (Amuesha), an Amazonian Peruvian ethnic group. Journal of Ethnopharmacology 2010, 127(1):175-192.

9. Anderson EN: Why Is humoral medicine so popular? Social Science and Medicine 1987, 15:133-145.

10. Anderson EN: Traditional medical values of food. In Food and Culture: A Reader. Edited by: Counihan C, Van Esterik P. London: Routledge; 1997:80-91.

11. Foster G: On the origin of humoral medicine in Latin America. Medical Anthropology Quarterly 1987, 1:355-393.

12. Lu H: Chinese System of Food Cures New York: Sterling; 1986.

13. Elisabetsky E: Traditional medicines and the new paradigm of psychotropic drug action. In Ethnomedicine and Drug Discovery, Advances in Phytomedicine. Volume 1. Edited by: Iwu M, Wootton J. Amsterdam: Elsevier; 2002.

14. Etkin NL, Ross PJ: Should we set a place for diet in ethnopharmacology? Journal of Ethnopharmacology 1991, 32:25-36.

15. Fessler DMT, Navarrete CD: Meat is good to taboo: Dietary proscriptions as a product of the interaction of psychological mechanisms and social processes. Journal of Cognition and Culture 2003, 3:1-40.

16. Meyer-Rochow VB: Food taboos: Their origins and purposes. Journal of Ethnobiology and Ethnomedicine 2009, 5:18[http://www.ethnobiomed.com/ content/5/1/18].

17. Mintz SW, Du Bois CM: The anthropology of food and eating. Annual Review of Anthropology 2002, 31:99-119.

18. Chevalier JM: Civilization and the Stolen Gift: Capital, Kin, and Cult in Eastern Peru University of Toronto Press; 1982
19. Dobkin de Rios M: A note on the use of ayahuasca among urban mestizo populations in the Peruvian Amazon. American Anthropologist 1970, 72:1419-1422.

20. Gebhart-Sayer A: Die Spitze des Bewusstseins Untersuchungen zu Weltbild und Kunst der Shipibo-Conibo Hohenschäftlarn: Klaus Renner Verlag; 1987

21. Luna LE: The concept of Plants as Teachers among four mestizo shamans of Iquitos, Northeast Peru. Journal of Ethnopharmacology 1984, 11(2):135-156

22. Luna LE, Amaringo P: Ayahuasca Visions: The Religious /conography of a Peruvian Shaman Berkeley: North Atlantic Books; 1991.

23. San Roman J: Visiones, curaciones y 'brujerias.'. Amazonia Peruana 1979, 2:7-32.

24. Jernigan K: Barking up the same tree: A comparison of Aguaruna ethnomedicine and canine ethnoveterinary medicine. Journal of Ethnobiology and Ethnomedicine 2009, 5:33[http://www.ethnobiomed.com/ content/5/1/33]

25. Lenaerts M: Substances, relationships and the omnipresence of the body: An overview of Ashéninka ethnomedicine (western Amazonia). Journal of Ethnobiology and Ethnomedicine 2006, 2:49[http://www.ethnobiomed.com/ content/2/1/49].

26. Shepard G: A sensory ecology of illness and therapy in two Amazonian societies. American Anthropologist 2004, 106(2):252-266.

27. Wilbert W: The pneumatic theory of female Warao herbalists. Social Science and Medicine 1987, 25(10):1139-1146.

28. Lenaerts M: When inter-ethnic botanical borrowing does not rely on obvious efficacy: Some questions from Western Amazonia. Ethnobotany Research and Applications 2006, 4:133-146[http://www. societedesamericanistes.be/Lenaerts\%20ethnobotany.pdf].

29. Chaumeil JP: Voir, Savoir, Poivoir: Le Chamanisme Chez les Yaguas du NordEst Peruvien Paris: Editions de l'Ecole des Hautes Etudes en Sciences Sociales; 1983.

30. Harner MJ: The Jivaro: People of the Sacred Waterfalls Berkeley: University of California; 1972.

31. Kleinman A: Patients and Healers in the Context of Culture Berkeley: University of California Press; 1980.

32. UNESCO: Intangible Cultural Heritage - Endangered languages.[http:// www.unesco.org/new/en/culture/themes/cultural-diversity/languages-andmultilingualism/endangered-languages/].

33. Beier C, Michael L: La condición actual del idioma indígena lquito y las claves factores afectando al proyecto de su recuperación.[http://www. cabeceras.org/lquito_Informe_2002.pdf].

34. Chaumeil J: La légende d'lquitos (version lquito). Bulletin Français d'Etudes Andines 1992, 21(1):311-325.

35. Beier C, Michael L: Diccionario lquito-Castellano.[http://www.cabeceras.org/ ildp06 iqt-span_131206.pdf].

36. Lai I: Time in the lquito language. Ph.D thesis University of Texas at Austin, Linguistics; 2009

37. Brown M: Topics in Iquito syntax: Word order, possession, and nominal discontinuity. Master's thesis University of Texas at Austin, Linguistics; 2004.

38. Code of ethics of the American Anthropological Association. [http:// www.aaanet.org/committees/ethics/ethcode.htm].

39. Bellier I: Los Pueblos Indios En Sus Mitos - Mai-huna, Tomo 2 Quito: AbyaYala Ediciones; 1993.

40. Bastien JW: Qollahuaya-Andean body concepts: A topographicalhydraulic model of physiology. American Anthropologist 1985, 87:595-611.

41. Colson $A B$, De Armellada C: An Amerindian derivation for Latin American creole illnesses and their treatment. Social Science and Medicine 1983, 17(17):1229-48.

42. Laderman C: Symbolic and empirical reality: A new approach to the analysis of food avoidances. American Ethnologist 1981, 8(3):468-493.

43. Mann HB, Whitney DR: On a test of whether one of two random variables is stochastically larger than the other. Annals of Mathematical Statistics 1947, 18(1):50-60.

44. Begossi A: Food taboos at Búzios Island (Brazil): Their significance and relation to folk medicine. Journal of Ethnobiology 1992, 12:117-139.

doi:10.1186/1746-4269-7-20

Cite this article as: Jernigan: Dietary restrictions in healing among speakers of Iquito, an endangered language of the Peruvian Amazon. Journal of Ethnobiology and Ethnomedicine 2011 7:20 